\title{
Lição inaugural
}

Droferida pelo prof. Rubião (Reira, na Faculdade de Medicina de São Daulo, ao reniciar o curso de clinica medica, a 17 de março de 1927.

Meus senhores:

Costumo receber as turmas de doutorandos, como outrora recebia os quartannistas, com a alma cheia de contentamento e o coração a se encher de illusões, para que ellas caiam tambem sobre a cabeça dos moços, como incentivo ao trabalho e amor ao estudo. Tem sido sempre esse o meu habito e desde que entrei para esta Faculdade, não tenho sido outra cousa senão irmão mais velho dos estudantes, ou como queiram que seja, sempre pae carinhoso e cheio de amor. Não distingo alumnos; todos têm sido meus filhos; todos os tenho abraçado num amplexo de forte sympathia e verdadeira estima. Perante mim todos são iguaes; não quero mais bem a um que a outro, quero igualmente e muito a todos. Têm feito elles parte integrante de minha familia, que é essa mocidade corajosa e intelligente que chega até aqui. Os que não têm a coragem de vencer ou os que são arrebatados para outras correntes não me têm conhecido, mas sabem por ouvir dizer, que existe um professor no $6 .^{\circ}$ anno que ama a juventude e nella confia, que estima os moços e delles recebe a força para caminhar na vida - tão penosa como ella é! Esse professor tem sido eu. Eu me ufano, com orgulho, dessa minha maneira de proceder, porque cada anno que se succede a outro é uma leva de amigos que me cahe entre'os braços é que passa, para deixar vir outra! Assim é a vida - a successão de vidas. Mas, hoje, a vossa presença me commove e me arrebata. Porque, senhores doutorandos vós não sois para mim somente os alumnos do $6 .^{\circ}$ anno medico. Vós sois mais. Vós sois os companheiros constantes e ha cinco annos, de meu filho querido. Vós viveis, com elle nessa communhão de espirito da mocidade; vós vos encontraes cedo nos hospitaes, vós estaes com elle á tarde nas aulas e á noite tambem não sei onde andaes, mas sempre com elle. Vós sois como seus irmãos.

Foi comvosco que se formou seu cerebro, foi comvosco que elle entrou nas batalhas do estudo; foi comvosco que elle pisou primeiramente as portas desta faculdade; foi comvosco que elle entrou 
nessas salas onde domina a caridade; é comvosco que elle daqui vae sair para os afanosos dias de lucta. Entrou menino, e sahe homem. Foste vós que o formastes; fostes vós que lhe destes a beber o leite do amor a medicina, foi vosso exemplo de trabalho que o encaminhou. Vós sois tudo para elle. E, eu, que me revejo nelle, que volto atraz na minha vida perto de 26 annos e olho sua figura juvenil e sympathica como me estou vendo naquelle saudoso tempo de minha existencia, encontro em vós outros que ides me ouvir como os meus companheiros de então, os meus collegas de cada, dia. Transporto-me em espirito a minha juventude, que se perdeu atraz da montanha da vida e cujo vestigio nem mais posso aperceber sendo em pegadas fugidias que cada hora escapam a impressão na retina da memoria, e vejo-me entre os meus amigos da Faculdade, entre meus companheiros de todo momento, entre aquelles que constituiram a minha familia, como vós outros constituis agora a de meu filho. E lembro me de tudo que passou, da amizade que me cercava, da sympathia que eu inspirava, das alegrias dos successos, academicos do anno das tristezas da separação. Recordo tudo isto neste instante para mim cheio de encantos.

Para vós, hoje é uma aula commum a que vindes assistir sem interesse, sem ligar maior valor ao novo professor sem acatar com respeitos as minhas palavras que entraeão e sahirão pelos ouvidos sem que seu echo faça vibrar qualquer cousa dentro de vossa intelligencia sem que fique alguma cousa de notavel a impregnar as dobras de vosso cerebro. Mas para mim não. Eu vos espero tranquillamente ha 5 annos integraes. Eu espero este momento ha tempos como um consolo para a minha vida de professor. Eu vos aguardo com o amor com que o velho pae das escripturas viu entrar portas a dentro de sua casa o filho prodigo. Eu recebo essa hora como uma bençam do ceu! Não penseis que são pieguices de velho ou fantasias de meu espirito essas palavras com que vos inicio hoje! São brotadas de meu coração. Imagine vós mesmo nesta situação e dizei-me si não é um conforto que Deus dá ao homem o iniciar seu filho amado nas trilhas de seu mesmo trabalho, arrancado com esforço e com assiduidade. Dizei-me si não é ventura que poucos attingem na vida tão cheia de difficuldades corôar com as minhas mãos mesmas os estudos de um filho, que só tem dado motivos de prazer, momentos de jubilo? Vede vós mesmo daqui a annos nesta situação, e olhae para a frente em tempos que nada passará sem obstaculos e luctas, e dizei-me si tenho ou não razão em receber-vos com o desvanecimento e o jubilo com que mal posso florir o meu verbo neste instante de gloria. A vida é triste senhores para todos que jornadeam com o fardo do trabalho nesta terra que Deus nos deu para o soffrimento para a humilhação, para combate. Mas, a do medico é a mais afanosa possivel a mais prenhe de obices, a mais cheia de penurias para o espirito humano. E, quando se chega 
até onde cheguei, abrindo caminho, com esforço e com dignidade com tenacidade e com honra, e se encontra ao ponto de dar a sua sucepção a um moço, como eu tenho o desvanecimento de entregar o meu patrimonio concebei que não exisste maior galardão na terra maior premio a seus esforços que esse. Tudo mais de nada vale. Os triumphos clinicos de que se fala, os casos felizes que se curou, uma dose homeopathica de gratidão que se guarda, tudo isto é pouco deante do jogar sobre a cabeça de seu filho umas poucas de flores colhidas na trajectoria sem as poucas de bençam recebidas no percurso. E' só que faço agora perante vós, que sois outros tantos filhos meus, que o amaes com o affecto de irmão, que conviveis com elle diuturnamente, que sos uma parcella e grande de sua vida, como sois um pedaço e grande tambem de meu coração.

Eu vos recebo com as abundancias de minha ternura, e os enthusiasmos de minha fé no vosso successo e espero me ouvireis não como um Mestre, mas como se fosse vosso pae a dar-vos os ultimos conselhos de que ireis necessitar na vossa vida pratica.

Vós não podeis, caros amigos, imaginar como é brutal, como é forte, a evolução da medicina. Estaes habituados a ouvir que a medicina não caminha, que todos os ramos da actividade do homem têm progressão rapida e intensa e no emtanto a medicina está parada. Pura illusão, engano completo! Fala-se isto porque não se cúra o cancer, porque não se cura a tuberculose, porque não se cura a syphilis, não se cura a lepra, não se cura o aneurysma, não se cura o mal de Pott, não se cura a paralysia geral, não se cura a esclerose arterial, não se cura uma infinidade de males. Mas isso não é argumento serio. Não se cura ainda mas vae se curar. Tudo isto que ahi vae exposto é o espantalho da humanidade, o terror das gentes que vivem no globo. Mas são problemas que ainda não foram resolvidos, mas que com certeza o serão mais depressa do que parece, em tempos mais ligeiros do que se precisa. Tudo isso vae cahir sob o cutelo da therapeutica. Tudo isso virá a desapparecer. Não vós espanteis, que não é para já, porque dir-me-heis então para que serve o se ser medico si as molestias vão findar? Não, tudo isto virá ainda a tempo de dedicardes vossas intelligencias e vossa actividade no exercicio desse penoso ministerio. Todos esses problemas, catados entre os que mais preoccupam o espirito dos investigadores, estão a ser estudados e revistos com cuidado e com entranhado amor. O problema do cancer é mundial, universal; até agora não se chegou a conclusão pratica alguma, não se sabe ainda ao certo si é mal hereditario ou si contagioso, não se sabe como evital-o e si é possivel fazel-o, ignora-se como cural-o mas, repentinamente, de uma hora para outra tudo vem á luz e o fulgor do descobrimento resplandecerá esse terreno, redimindo milhares de milhares de vida.

E' preciso não esmorecer na luta e continuar nas pesquizas. Com o animo cheio de coragem é a esperança a bafejar o coração. 
A tuberculose é outra peste a nos incommodar, atirando ao fundo do sepulchro tantas vidas aproveitaveis, dizimando as populações-civilisadas com a implacabilidade de sua acção malfazeja. Mas a sua hora está a se contar, seus dias a se numerar. Não será a sanochrysina que a dissolverá, mas sim qualquer outra medicação especifica que a fárá ruir por terra do pedestal de maldade em que se acha installada ha seculos e seculos. Evital-a já se pode; conhecer os processos pathogenicos já se os conhece; marcar-lhe a evoluçãão já é permttido, o que falta é cural-a, esse pouco que ha de brotar um dia do laboratorio e empanar-lhe o luscofusco maldito.

A syphilis está quasi a desapparecer. Não penseis que exagero, não. E' um facto. Si ainda não se conseguio matal-a de vez, observa-se, entretanto, que já não mata como outr'ora - os seus effeitos perniciosos vão desapparecendo. Onde os casos de aneurysmas tão frequentes como outr'ora? Onde os muitos doentes de tabes como antigamente? Onde os paralyticos geraes que outr'ora enchiam os serviços de hospicio e dos hospitaes? Não tem comparação, o que se vê hoje e o que se encontrava annos atraz, antes da therapeutica, arsenical. A medicação de Erlich deu um encontrão formidavel em todos esses processos morbidos e hoje pode-se dizer sem receio de se estar dizendo uma heresia, que tem estas cousas graves da vida quem quer tel-as. Quem as não deseja possuir, trata-se, que as não tem mais. Desapparecerão da scena morbida no dia em que fôr noção geral e segura que a syphilis é curavel e que o tratamento intensivo, si a não curar evita, entretanto, maiores males, os males mortaes. Que progresso na medicina esse! retirar uma das causas mais lethaes que existiam! Jogar no esquecimento essas cousas tristes que a syphilis faz - a ataxia locomotora, a paralegia espasmodica, a ptose palpebral, o delirio de grandeza, os aneurysmas, a cegueira rapida todas essas entidades que trazem o sello fatal da incapacidade e da morte! Hoje não vereis mais o que eu vi. Não presenciareis mais o que presenciei, quando moço. As salas do hospital do Rio em meu tempo ou tinham pleureticos e tuberculosos (uma cousa só) ou hemiplegicos e tabidos ou os aneurysmaticos. A não ser nas epocas de incursão da febre amarella outra coisa se não via. E que medicação empregavamos? Nada. Para os pleureticos era se tirar o liquido e nada mais - e a conclusão era certa - a morte em cachexia quando não intercorria a purulencia do derrame por infecção de picada. Para os syphiliticos em todas as suas manifestações - o arose de Gilbert - a salsaparrilha e a caroba, as fricções mercuriaes e, nada mais. Só no fim de meu curso é que surgiram as injecções de biodeto hydrargirio que se applicavam na dose de 0,004 de 2 em 2 dias na solução de Panas e em seringa que se não podia esterelisar, pois era feita de vidro, metal e páo. Tudo mais veiu nestes 20 annos, - as picadas de mercurio a substituir as pilulas de Ricord e Dupuytrese; o 606 e o 914 a esterelisar o sangue; as injecções de Bismutho a completar o tratamento. A reacção de Wassermann deu a chave do pro- 
blema, a certeza da cura, embora não se deva confiar nella senão com a relatividade com que se tem obrigação de se apoiar nos factos de laboratorio. O progresso nesse terreno da medicina é verdadeiramente assombroso e a clinica no futuro estará armada de meios de debellar um dos factores mais deprimentes das raças, de extingir um dos elementos mais perniciosos á humanidade. Computae os effeitos deleterios da syphilis com o resultado da therapeutica e haveis de ver que esse problema é dos mais relevantes e que se acha sinão totalmente resolvido pelo menos em quasi franca solução. A lepra ha de tambem desapparecer; a sua prophylaxia é conhecida, suas lesões não passam ignoradas, suas manifestações clinicas descobrem-se no nascedouro, de sorte que a questão é, apenas de therapeutica. Os governos pódem localisal-a, podem. impedir a sua propagação, a sua disseminação. Não se tem, entretanto, até hoje realisado a sua cura; pode-se mesmo consideral-a molestia eminentemente incuravel, mas tempo virá e não longinquo em que até essa desgraçada entidade morbida, que desceu sobre os homens como um castigo celeste terá que se dobrar deante do agente medicamentoso, que a fará entrar no ról das desgraças historicas: Oxalá possamos assistir a esse advento, que será uma das maiores glorias da medicina a derramar as bençams de seus favores sobre os homens contaminados da mais degradante e repulsiva das molestias. A esclerose arterial não se cura, porque é processo morbido degenerativo, mas é evitada. Cesse a syphilis seu poder infectante e degenerativo, empenhem-se os homens de coração e de cerebro na luta ferrenha contra o alcoolismo; lutese contra as infecções e contra as intoxicações, terminem-se na terra as ambições, dominem-se as emoções - que este corpo pathologico ha-de diminuir sua acção deleteria. Mas é a idade quem faz a arterio esclerose. São as intoxicações que a idade accumula quem agora, acabadas as causas - e ha de haver tempo que o seu fim chegue - a esclerose arterial não ha de encher as cartas mortuarias.

Isto tudo foi dito para accentuar que não têm razão os que dizem que a medicina não avança. Não, senhores meus. Si eu fosse fazer um parallelo entre a medicina de hoje e a de 10 annos atraz, vós ficarieis assombrados dessa evolução majestosa. Em todos os territorios organicos pode-se dizer sem medo de erro, a transmutação é completa.

Olhae a cardiopathologia e vereis que a lesão orificial que outr'ora era tudo substituio no seu valor o estado myocardio - Esta noção é capital. Outr'ora dava-se importancia á lesão, a sua extensão, ás suas manifestações esthetocopicas - Uma lesão grande era um pavor - Uma espada de Damocles suspensa sobre a cabeça do mortal; uma pequena era compativel com existencia prolongada. Entretanto, observava-se que repentinamente o que possuia diminuta lesão ou morria em syncope ou entrava no estado de asyslotia, como então se chamava, emquanto o outro continuava vivo 
e trabalhando annos em fóra. O que aconteceu? E' que o myocardio cedeu na primeira das hypotheses, emquanto continuasse integro na segunda. Hoje o que vale é o myocardio. Elle é quem dá o tom ás lesões, e quem segura a chave da vida. Tudo se modificou desde que a therapeutica transformou-se tambem - Olhae a pathologia renal e vede como é differente tudo aquillo! Não mais nephrites intersticiaes, não mais nephrites parenchymatosas, não mais uremias a torto e a direito a matar gente que nunca morreu de uremia. Hoje tudo está definido e facil. A therapeuthica beneficou-se immensamente.

Nesse capitulo de medicina o professor espanta e mararavilha. As concepções hodiernas simplificaram o problema e o medico orienta-se seguro no turbilhãão de phenomenos morbidos que outr'ora eram classificados a "trouxe mouxe" de phenomeno de brightismo.

A intoxicação uremica era uma cousa complicadissima que ninguem entendia. O que acontecia era que deante de um quadro morbido assustador em individuo que perdia albumina o diagnostico era certo. mas errado - "uremia"

Nada mais facil. Como provar que não era? Bastava um medalhão qualquer affirmar que os outros tinham que se calar. Como sustentar o contrario? Hoje não - é uremico quem tem uréa, no sangue em proporções avantajadas á toda normal. O diagnostico de uremia só pode ser feito com esse elemento. Tudo que não for isto, está errado. E' como um axioma indestructivel.

Si fordes a pathologia hepatica veres o mesmo facto - a luz moderno que innunda esse campo da medicina. A cirrhose de Laennec que tomou um contra formidavel, já não é mais o que era - hoje é uma hepatite, podendo ser occasionada por causas diversas, emquanto até bem pouco tempo só o alcool poderia geral-a.

E, assim por deante. Tudo em passos gigantescos. E' natural que a therapeutica não esteja muito mais avançada, mas é que ella se basea sobre os conhecimentos da pathogenia, que se está refazendo. E' por isso que se grita que tudo está atrazado e que as gentes morrem da mesma maneira. E' um engano que cede deante um estudo aprofundado, como infelizmente não posso fazer agora para não vos fatigar e não vos deixar a impressão de professor cacete, que a ninguem é lisongeiro.

Tendes por isto que acompanhar a evolução da medicina. Eu dar-vos-ei o passado e o presente. Mostar-vos-ei em cada caso como se pensava e como se pensa. O futuro a vós pertence. Quando entrardes nelle, com os elementos que daqui levardes a vossa tarefa será mais facil e vosso espirito se banhará, com mais ligeireza, com os fogos das conquistas. 
Serei vosso conductor, levando vossa attenção pelos caminhos desbravados, afim de que possaes guardar desse professor a impressão de que não vos fatigou com as asperezas da estrada, a retirarlhes os embaraços, antes vos apontou a trilha segura na conquista do saber.

Confiae em mim, que dar-vos-ei o pouco que sei com a mesma cordialidade, esperando, em vossa constancia ,em vossa assiduidade, em vossa criteriosa attenção para que possamos attngir o fim do curso, amigos e irmãos, nessa campanha do estudo, em pról do genero humano.

Laboratorio de Chimica e Microscopia Clinicas DOPHARMACEUTICO MALHADO FILHO

ANALYSES DE URINA, SANGUE, SUCCO GASTRICO, LEITE, FÉzES, ESCARROS, FALSAS MEMBRANAS, REACÇÕES DE WASSERMANN, DE RONCHÉSE E DE VIDAL, AUTOVACCINA.
O LABORATORIO FORNECE VIDROS ESPECIAES PARA A COLHEITA DE URINA, ACOMPANHADOS DAS NECESSARIAS INSTRUCÇÕES. PAGA MENTO Á VISTA

ABERTO DIARIAMENTE DAS 9 ÁS 18 HORAS

Rua São Bento N. $24=\left(2 .^{\circ}\right.$ andar $)-$ Telephone=Central, $2572-$ S. Paulo = Brasil 